\title{
Extracurricular Educational Programs and School Readiness: Evidence from a Quasi-Experiment with Preschool Children
}

\author{
Anna Makles \\ Kerstin Schneider
}

CESIFO WORKING PAPER NO. 5778

CATEGORY 5: ECONOMICS OF EDUCATION

FEBRUARY 2016

An electronic version of the paper may be downloaded

- from the SSRN website:

- from the RePEc website:

wWw.SSRN.com

www.RePEc.org

- from the CESifo website:

www.CESifo-group.org/wp 


\title{
Extracurricular Educational Programs and School Readiness: Evidence from a Quasi-Experiment with Preschool Children
}

\begin{abstract}
This paper adds to the literature on extracurricular early childhood education and child development by exploiting unique data on an educational project in Germany, the Junior University (JU). Utilizing a quasi-experimental study design, we estimate the causal short-run effect of JU enrollment on ability measures and show that attending extra science courses with preschool classes leads to significantly higher school readiness. Attending classes at JU increases school readiness by approximately $2.18 \%$ which corresponds to $1 / 5$ of a standard deviation of the ability score. The result is plausible and passes various robustness checks.
\end{abstract}

JEL-Codes: I200, I210, I280, J130.

Keywords: early childhood education, extracurricular activities, early interventions, school readiness.

Anna Makles

Wuppertal Research Institute for the Economics of Education (WIB)

University of Wuppertal

Gaußstr. 20

Germany - 42119 Wuppertal

makles@wiwi.uni-wuppertal.de

www.wib.uni-wuppertal.de
Kerstin Schneider*

Wuppertal Research Institute for the Economics of Education (WIB)

University of Wuppertal Gaußstr. 20

Germany-42119 Wuppertal

schneider@wiwi.uni-wuppertal.de

www.wib.uni-wuppertal.de

Phone: +49(0)202 4392483

*corresponding author

January 2016 


\section{Introduction}

Educational attainment, earnings, the probability of employment, and health are persistently and profoundly affected by early childhood conditions and development in early life. This is consensus in the public debate and supported by empirical research (Almond/Currie 2011). Besides parental support and child health, the quality of child care and schools, as well as early intervention programs determine schooling outcomes and returns to education. Early investments yield high long-lasting private and public returns, in particular for children from disadvantaged backgrounds (among others Almond/Currie 2011, Duncan/Magnuson 2013, Currie 2001, Burger 2010). Whether disadvantages in early childhood can be cured by early intervention programs or child care is still an open question. However, there is encouraging empirical evidence (Duncan/Magnuson 2013; Ruhm/Waldfogel 2012; Belfield et al. 2006; Barnett 1995; Heckman et al. 2010; Lochner 2011, Deming 2009). Studies find long-lasting effects of child care and intervention programs on attainment and other non-schooling outcomes, even if the effect on cognitive test scores might not be long lasting (Heckman/Raut 2013, Blau/Currie 2006).

Besides general effects of child care and early intervention programs for disadvantaged children, only little is known about the effects of additional and voluntary educational activities for children in general. More recently, non-academic activities like sports have been shown to affect educational and labor market outcomes (e.g. Stevenson 2010; Lechner/Downward 2013; Lipscomb 2007). However, sport activities can have negative effects on risk behavior like drinking or using drugs (Eccles et al. 2003) whereas social activities are shown to reduce risky behavior. Nevertheless, none of these studies focuses on educational activities or educational activities in early childhood. Hence, more research about how and if at all additional activities in early childhood affect short-run and later life outcomes is necessary. 
One study addressing the effect of sport activities in early childhood is Felfe/Lechner/Steinmayr (2011). The authors find positive effects on schooling outcomes and non-cognitive skills like peer relations. Similarly, positive effects of sports and private music lessons during childhood and adolescence on schooling outcomes are reported in Pfeifer/Cornelißen (2010) and Hille/Schupp (2015). However, the effect of extracurricular educational activities in early childhood has not been evaluated yet. Moreover, since intervention programs and extracurricular activities cause additional costs, issues of cost effectiveness ought to be addressed as well.

Related to the effectiveness and in particular cost effectiveness of early childhood education programs is the question of how to organize them. For instance, in Germany there is a fear of shortages in STEM (Science, Technology, Engineering, and Mathematics) qualifications of the labor force. Therefore, fostering children's interest in those fields is a popular demand. But who should teach science classes for preschool children: Professionals or trained preschool educators? Kindergarten teachers are no science experts nor are science labs available in a typical kindergarten. Hence, there are arguments for a more centralized (preschool) science education, despite additional costs for setting up and running such an institution.

An example of a German initiative to improve science education in kindergarten by educating preschool teachers - and hence an example of a decentralized extracurricular approach - is the 'Haus der kleinen Forscher' (House of little scientists). The initiative is supported by the Federal German Ministry of Education and Science (BMBF) with a budget of almost $€ 8$ million in 2012 and $€ 9$ million in 2013 . ${ }^{1}$ So far, there has been no evaluation of either the causal effects on interest in science or cognitive outcomes nor the cost effectiveness.

\footnotetext{
1 The 'Haus der kleinen Forscher' is a joint initiative of the BMBF and the Telekom foundation (the annual reports are available at: http://www.haus-der-kleinen-forscher.de)
} 
Alternative programs are science labs for children and children's universities ${ }^{2}$ that aim to foster interest in science and research. Those classes are taught by science experts or STEM students in universities or laboratories. The courses are typically short, e.g. single courses during school vacations or after school, and mainly target children in primary or secondary school. Whether attending these science classes has a positive effect on interest in science, schooling, let alone later-life educational and labor market outcomes, is an open question.

The present paper adds to the literature on voluntary extracurricular early childhood education by exploiting a quasi-experimental setting in an educational project in Germany. The Junior University ${ }^{3}$ (JU) is a centralized non-profit educational institution. It is fully financed by private donations and explicitly intended to be complementary to kindergarten and school in the region. In this paper we study the short-run effect of JU enrollment in science classes on the school readiness of children. Hence, the focus is not on raising children's interest in science, which is hard to measure. Instead, we analyze the effects on cognitive outcomes. To measure JU's return to educational outcomes, we use data from different sources and study whether attending a science course with the preschool class affects school readiness as assessed by the compulsory school entrance examination. Our results show that attending JU leads to higher school readiness. The size of the effect is $1 / 5$ of a standard deviation of the school readiness measure which corresponds to an age effect of more than four months. Although the effect of JU attendance on school readiness is small in terms of score improvement (less than three additionally completed tasks in the school readiness test), the results are plausible and robust. In addition, we provide first and tentative evidence for the short-run cost effectiveness of JU.

2 For example HandsOn Science in the UK and US, ScienceLab Kinder.Wissen.Mehr in Germany (Schettler 2010). Children's universities can be found across Europe, especially in Germany and the UK.

3 Full name: Junior Uni - Wuppertaler Kinder- und Jugend-Universität für das Bergische Land gGmbH ( $\mathrm{gGmbH}=$ non-profit company with limited liability). More information (in German) is available at www.junioruni-wuppertal.de. 
This paper is organized as follows: In Section 2 we provide some information about Junior University. Section 3 describes the data, and in Section 4 we discuss our empirical strategy. Section 5 presents the results, robustness checks and a tentative cost-benefit analysis. Finally, Section 6 concludes and briefly discusses the results.

\section{Junior University}

Junior University (JU) was launched in December 2008 as a permanent private non-profit institution, entirely financed by private donations. It is located in Wuppertal, a city with a population of about 350,000 in the German federal state of North Rhine-Westphalia. JU offers courses for children and young adolescents with a focus on science, mathematics and engineering. The pedagogical concept was developed by a physics professor, who created a popular German science TV show for children called 'Löwenzahn' in cooperation with a school teacher familiar with teaching disadvantaged children.

JU aims at raising interest in STEM by offering mainly hands-on experimental courses. Unlike other university programs for children, it is not a temporary institution within an educational institution but a permanently established independent body. Furthermore, it is explicitly not targeted only at gifted or advantaged students but addresses all children and youths between the age of 4 and 20 (or the end of secondary school), regardless of their educational or social background.

There are two types of enrollment at JU: individual enrollment or group enrollment. Group enrollment is popular, in particular among kindergarten preschool classes (last year before primary school). The courses are generally organized in four 90-minute units and run on a weekly basis. They address different age groups (4-6, 7-10, 11-14, and 14 and older) and are not taught by school teachers but by university professors, undergraduate and graduate 
students, local entrepreneurs or citizens. The course fee is $€ 5$ per child. ${ }^{4}$ Obviously, the fee does not cover costs. The low fee was chosen to not deter children from low-income families from participating. For families who cannot afford the low fee, JU arranges a sponsor, e.g. a local company, to cover the fee.

From December 2008 through spring 2012 JU offered 1,091 courses and received 13,648 applications. Since the courses are popular, with the number of applicants exceeding the number of slots each term, allocation is on a first come-first served basis. This does not apply to kindergarten courses. The slots for preschool classes have not been limited to offer broad access to JU in particular for the youngest. Almost a quarter $(21.26 \%, 232$ courses $)$ of the courses were offered for preschool groups with 2,964 preschool children.

Since the focus in this paper is on preschool education, we restrict our attention to kindergarten children who attend JU with the entire preschool class. In 2011, Wuppertal had 185 daycare institutions (private parental initiatives and public kindergartens) of which 84 participated in JU courses with at least one preschool class. Hence, a problem in our identification strategy may arise from the selectivity of the participating kindergartens. The heterogeneity of the districts in Wuppertal as well as the level of segregation is high. Some kindergartens are located in highly disadvantaged areas of the city. However, the participating kindergartens are not a positive selection of all kindergartens in the city. For instance, there is no significant difference in the distance from kindergarten to JU or the share of immigrant children between participating and non-participating institutions. Moreover, socioeconomic status variables like average disposable income or share of welfare recipients do not differ between participating and non-participating kindergartens.

\footnotetext{
${ }^{4}$ Courses can also be organized in six or eight 90-minute units or as full-day courses. The fee for these courses may be higher, up to $€ 10$. Kindergarten courses run for four weeks only and the course fee is $€ 5$. The fee for preschool classes is generally paid for by the kindergartens.
} 


\section{Data and ability measures}

To estimate the short-run causal effect of JU attendance on school readiness, we use administrative data that allows us to distinguish between a treatment group (children enrolled at JU with the entire kindergarten preschool class) and a control group (peers from the same kindergarten who did not participate). The data stems from various sources and includes individual level information, information on the level of the residential city block and also information on income on the postal code level. Data on individuals is drawn from the Schuleingangsuntersuchung (SEnMed - school entrance medical examination) a compulsory and standardized school readiness assessment. It provides information on abilities, kindergarten enrollment and background characteristics like age, gender, residence and ethnic origin. Information on JU participation is taken from the administrative data of the JU. This information is linked to the SEnMed data. We supplement the individual level data with data on the city block level to describe the children's neighborhood. A city block is a small administrative unit with on average about 140 residents. In 2010, Wuppertal had 2441 inhabited city blocks. The data provides detailed information on ethnicity, employment and welfare dependency. To further enrich our city block data, we add income indicators that are available on the slightly more aggregated postal code level. The different data sources and ability measures are described in more detail in the following sections.

\subsection{School entrance medical examination}

The school entrance medical examination (SEnMed) is a compulsory and standardized examination of all children. Hence, the SEnMed is a census of all preschoolers. On average, the children are 5 years and 11 months old when examined because the exam is scheduled according to birth date. SEnMed is conducted to assess the previous and current health status as well as the cognitive and non-cognitive development of preschoolers in order to attest school readiness. The data includes the retrospective and current health status (e.g. birth 
weight, obesity, ear and eye conditions, social and emotional development) and several dimensions of cognitive and non-cognitive abilities. In addition, the data comprises individual characteristics like age, gender, ethnic origin as well as information on the kindergarten.

In our analysis we use data of 5,669 preschool children from two cohorts born between 2003 and 2005 who took the SEnMed between 2009 and 2011..$^{5}$ The children's abilities were assessed during the SEnMed using state-wide standardized tests. ${ }^{6}$ Theoretically, the lowest possible score is zero (no task completed) and the maximum depends on the number of tasks within a test area. There are nine test areas corresponding to different ability dimensions such as visual and analytical skills, numerical and quantitative skills, language skills, and fine and gross motor skills. Typical tests are retracing figures, visual discrimination, counting, estimating and comparing quantities, neglect tests to assess visual and selective attention, use of prepositions, plural forming and repeating made-up words. Gross motor ability is assessed by asking children to jump on one leg or to walk on a straight line.

On the basis of these test results and the child's health status physicians decide whether a child might enroll in primary school or be held back for a year. Note that there is no threshold or cutoff for passing the SEnMed exam. Hence, from the physician's point of view, the test results represent a one-dimensional latent scale of school readiness. We follow this idea and reduce the nine ability dimensions to a one-dimensional scale of school readiness. The scale is generated using an exploratory factor analysis. The results of the factor analysis confirm the conjecture of a one-dimensional factor, with about $97 \%$ of the variance in the ability items being explained by the first factor. ${ }^{7}$ In the analysis, we use the factor of school readiness as our outcome variable. To better interpret the estimation results, we transform the

\footnotetext{
5 The first cohort comprises 2,809 children born between 09/01/2003 and 08/31/2004 whose SEnMed took place between mid-August 2009 and mid-July 2010. The second cohort comprises 2,860 children born between 09/01/2004 and 09/30/2005 whose SEnMed took place between September 2010 and July 2011.

6 The tests are confidential and the test items are not publicly available.

7 The overall KMO criterion is 0.8285 ; item KMO criteria lie between 0.7070 and 0.9251 .
} 
factor to a scale between 0 and 100. The highest value of school readiness (100\%) corresponds to a score of 129 successfully completed tasks. The distribution of school readiness for the full sample $(n=5,669)$ is shown in Figure 1 .

Figure 1 School readiness in $\%(n=5,669)$, density and performance bands

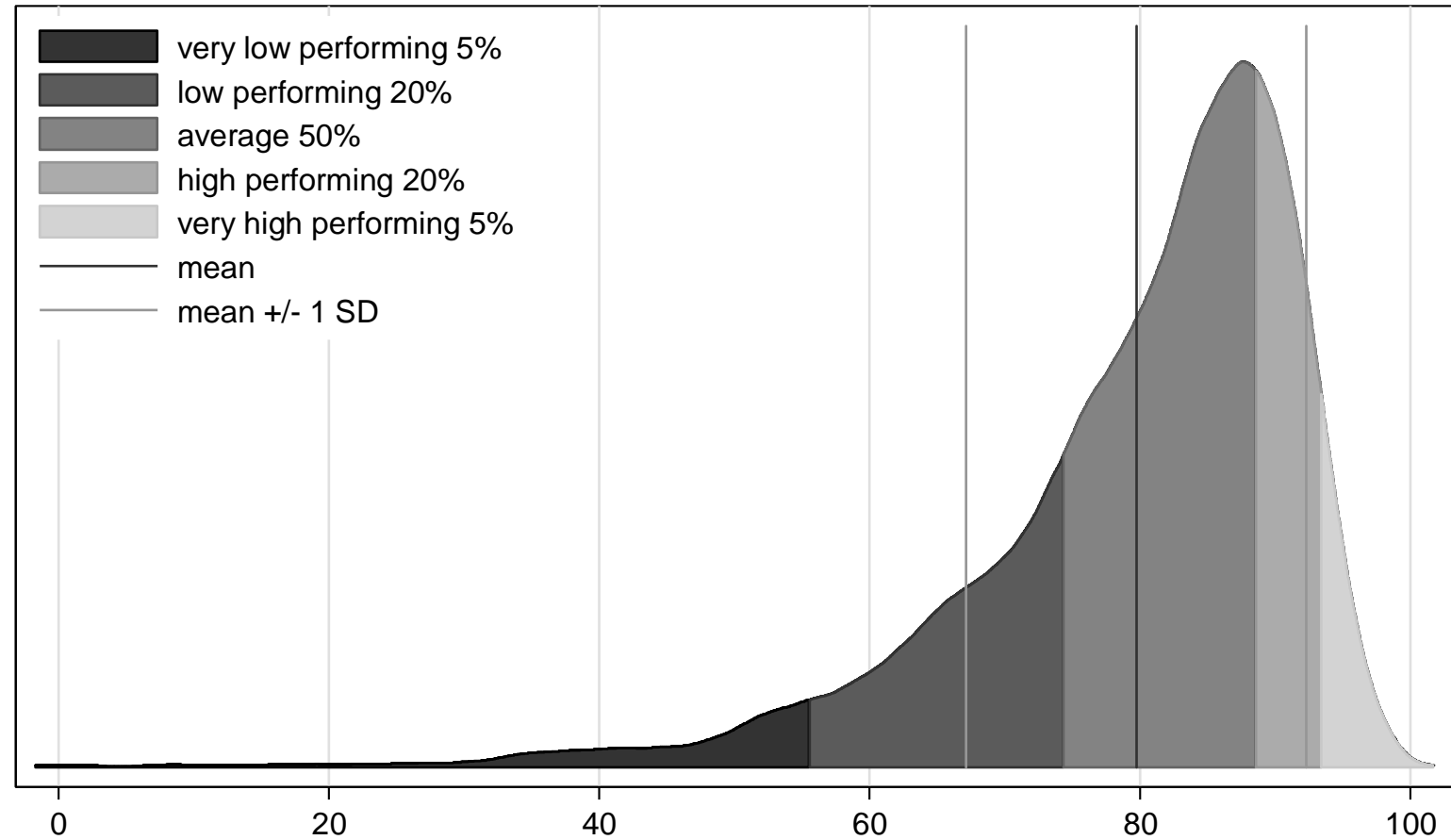

Notes: average school readiness: $\bar{y}=79.73, s_{y}=12.57$; percentiles: $y_{0.01}=35.95, y_{0.05}=55.53, y_{0.25}=$ $74.32, y_{0.50}=83.01, y_{0.75}=88.56, y_{0.95}=93.40, y_{0.99}=96.04$.

The performance bands in Figure 1 characterize five groups: the very low performing 5\%, low performing $20 \%$, medium $50 \%$, high performing $20 \%$ and the very high performing $5 \%$. Average school readiness is $79.73 \%(\mathrm{SD}=12.57)$ and the distribution is left-skewed. The weakest $5 \%$ of the children have a school readiness score of at most $56 \%$, whereas the medium $50 \%$ of the children have school readiness values of between $74 \%$ and $89 \%$.

In addition to information on abilities, there is a large set of background variables in the SEnMed data. Table 1, column (1) summarizes the data and in column (2) we describe the two cohorts. The sample comprises 5,669 children, $51.08 \%$ of whom are boys; $36.57 \%$ of the children are immigrants, where migration status is defined by the language spoken with the 
child during the first four years. If the parents report a language other than German, the child is said to have a migration background.

Table 1 Descriptive statistics, full sample and by cohorts

\begin{tabular}{|c|c|c|c|}
\hline & \multirow{3}{*}{ Total } & \multicolumn{2}{|c|}{$(2)$} \\
\hline & & \multicolumn{2}{|c|}{ Cohort } \\
\hline & & 1 & 2 \\
\hline Full sample size & 5,669 & 2,809 & 2,860 \\
\hline Average age at examination & $\begin{array}{c}5.95 \\
(0.2077)\end{array}$ & $\begin{array}{c}\mathbf{5 . 9 6} \\
(0.2139)\end{array}$ & $\begin{array}{c}\mathbf{5 . 9 4} \\
(0.2010)\end{array}$ \\
\hline$\%$ boys & 51.08 & 50.44 & 51.71 \\
\hline$\%$ with migration background & 36.57 & 36.67 & 36.47 \\
\hline Average time in kindergarten (in years) & $\begin{array}{c}2.74 \\
(0.7519)\end{array}$ & $\begin{array}{c}\mathbf{2 . 7 9} \\
(0.7481)\end{array}$ & $\begin{array}{c}\mathbf{2 . 6 8} \\
(0.7519)\end{array}$ \\
\hline Number of siblings in $\%$ & 21.86 & 21.72 & 21.99 \\
\hline 1 & 46.60 & 47.24 & 45.98 \\
\hline 2 & 20.14 & 20.08 & 20.21 \\
\hline 3 & 7.14 & 6.51 & 7.76 \\
\hline 4 or more & 4.25 & 4.45 & 4.06 \\
\hline severely underweight & 2.77 & 2.48 & 3.05 \\
\hline underweight & 6.48 & 6.68 & 6.28 \\
\hline normal (healthy weight) & 78.37 & 78.39 & 78.36 \\
\hline overweight & 6.84 & 7.04 & 6.64 \\
\hline obese & 5.54 & 5.40 & 5.67 \\
\hline$\%$ low birth weight & 7.35 & 7.76 & 6.95 \\
\hline$\%$ health record presented & 93.91 & 94.16 & 93.67 \\
\hline$\%$ with U7a (medical screening at age $34-36$ months) & 87.22 & 87.46 & 86.99 \\
\hline$\%$ vaccination record presented & 92.59 & 93.09 & 92.10 \\
\hline$\%$ with tetanus vaccination & 91.69 & 91.81 & 91.57 \\
\hline$\%$ reduced visual acuity & 21.50 & 22.11 & 20.91 \\
\hline$\%$ partial hearing loss & 8.08 & 9.97 & 6.22 \\
\hline$\%$ with behavioral problems & 6.28 & 8.37 & $4.23^{\text {a) }}$ \\
\hline $\begin{array}{l}\text { Average \% of welfare dependent households } \\
\text { with children per city block }\end{array}$ & $\begin{array}{c}29.08 \\
(21.03)\end{array}$ & $\begin{array}{c}\mathbf{3 0 . 1 5} \\
(21.48)\end{array}$ & $\begin{array}{c}\mathbf{2 8 . 0 2} \\
(20.52)\end{array}$ \\
\hline $\begin{array}{l}\text { Average } \% \text { of immigrant children } \\
(<6 \text { years }) \text { per city block }\end{array}$ & $\begin{array}{c}53.66 \\
(28.86)\end{array}$ & $\begin{array}{c}53.34 \\
(28.96)\end{array}$ & $\begin{array}{c}53.96 \\
(28.76)\end{array}$ \\
\hline $\begin{array}{l}\text { Average disposable income (in } € 10,000 \text { ) } \\
\text { in postal code area }\end{array}$ & $\begin{array}{c}3.8788 \\
(0.8940)\end{array}$ & $\begin{array}{c}3.8870 \\
(0.8912)\end{array}$ & $\begin{array}{c}3.8707 \\
(0.8968)\end{array}$ \\
\hline
\end{tabular}

Notes: Standard deviation in parentheses; bold figures indicate significant differences between groups $(p \leq 0.05)$ based on t-tests (for age, kindergarten, city block and postal code information) and $\chi^{2}$-tests (for the other variables); ${ }^{a}$ Difference is significant due to a high increase in the category 'examination was not possible' (assessment is not compulsory). 
On average, the children have attended kindergarten for 2.74 years (about 2 years and 9 months) before taking the school entrance exam. This is expected, as children in our data are entitled to a place in kindergarten after their third birthday. ${ }^{8}$ About $46.60 \%$ of the children have one sibling; $4.25 \%$ have four or more siblings. The share of overweight or obese children is slightly larger than the share of (severely) underweight children. About $78 \%$ have a healthy weight. Table 1 column (2) indicates few significant differences between the two cohorts. The difference in 'age at examination' and 'time in kindergarten' is plausible and due to an earlier cutoff date for primary school enrollment in North Rhine-Westphalia in 2011. Due to the earlier cutoff date, the second cohort comprises 13 months of births. Hence, the average age in the second cohort is below the average age of the first cohort. The significant difference in 'behavioral problems' is also explained by the different sizes of the cohorts. Assessment of behavioral problems is not compulsory in the SEnMed and, due to the larger second cohort and resulting time constraints, the assessment was more often omitted (there is a corresponding increase in the category 'examination was not possible'). As there is no apparent explanation for the significant difference in 'partial hearing loss' between the two cohorts, we control for this variable and the cohort in the estimations.

\subsection{Administrative data on socioeconomic status}

The child's address information is used to merge individual data (from the SEnMed) and information on socioeconomic status on the level of the city block or the postal code area. The city block data is no individual level data. However, it indicates the probability of being member of a social group. For instance, if $20 \%$ of the children in a given city block live in low-income families, a child living in this city block is said to have a $20 \%$ probability of living in a low income family. Enriching the individual-level data by city block data is

\footnotetext{
${ }^{8}$ Since 1996 (2013) children in Germany are entitled to a place in kindergarten at the age of three (after their first birthday).
} 
important because the SEnMed data does not include individual-level information on socioeconomic status. Thus, following earlier work (Schneider et al. 2012; Riedel et al. 2010), the city block information is used as a proxy for a child's socioeconomic status. We describe the residential environment by variables like the risk of poverty (defined as the share of welfare-dependent private households), the unemployment rate and the share of immigrants.

Since city block data only indicates low status (like unemployment, poverty, etc.), additional variables describing neighborhoods of medium or high level socioeconomic status are helpful. Here we use additional data on disposable income per household ${ }^{9}$. The variable allows a more comprehensive description of the socioeconomic status in the neighborhood. This data is only available for the eight-digit postal code area, i.e., 368 areas in Wuppertal (Figure 2).

Figure 2 Annual disposable household income in $€$ in Wuppertal

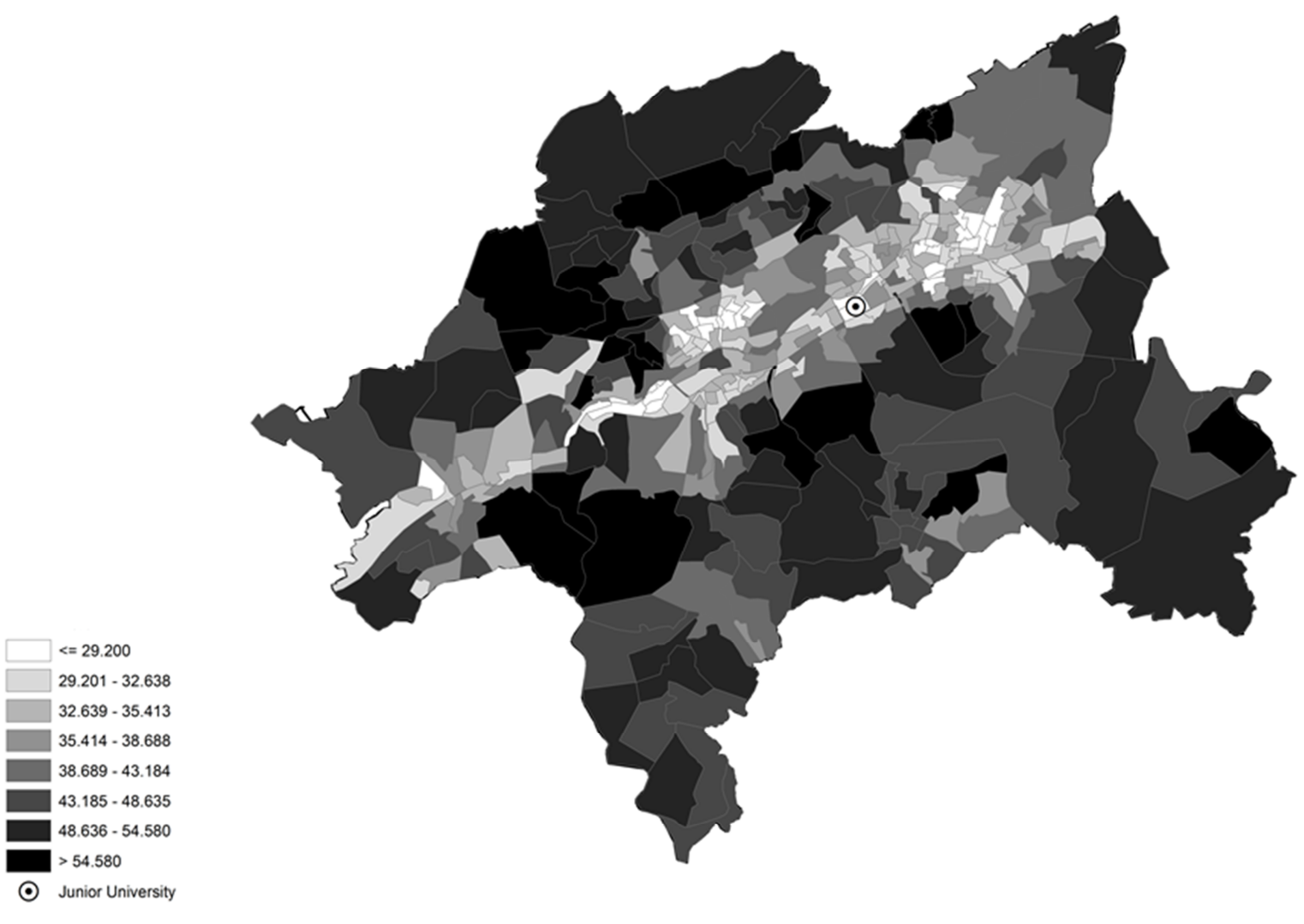

\footnotetext{
9 The data is provided by the microm $\mathrm{GmbH}$.
} 
Table 1 reports descriptive statistics for the city block and postal code variables. The average share of welfare dependent households with children in a city block is $29.08 \%$, the average share of immigrant children is $53.66 \%$ and the average disposable income amounts to 38.79 thousand $€$ per year. The decreasing welfare dependency between the cohorts reflects a common trend. Between 2008 and 2010 the overall welfare dependency rate in Wuppertal declined from $20.26 \%$ to $18.58 \%$.

\section{Empirical strategy}

The effect of attending JU courses on school readiness is assessed by using the two enrollment cohorts of preschool children (SEnMed in 2009-2010 and 2010-2011) and computing the one-dimensional factor of school readiness discussed above. Having children from two cohorts allows exploiting variation within kindergartens, because kindergartens may enroll some but not all preschool classes at JU. We use the within kindergarten variation to estimate the causal effect of JU attendance by comparing the performance of children from the same kindergarten. The effect can be interpreted as causal because JU attendance is exogenous, as will be explained below.

\subsection{Exogeneity of the treatment}

The structure of our data regarding the treatment status is illustrated in Figure 3.

The data comprises 5,669 children. 1,273 have attended at least one course at JU (22.46\%). Most of these children (1,055 or $82.88 \%)$ were enrolled with their preschool class (as opposed to individual enrollment). As we argue in more detail below, participants enrolling with their preschool classes are not affected by self-selection issues. Hence, these children and their kindergarten peers can be used to identify the JU effect.

Kindergartens enroll entire preschool classes of on average 14 children at JU. However, we observe within kindergarten variation in participation at JU because one 
preschool class is enrolled and another class in the same kindergarten is not. The children of participating kindergartens who do not attend JU are labeled 'untreated' or 'control'. In addition, we also exploit within preschool within class variation because some children attend JU with their preschool class but take the SEnMed prior to the JU class ( $n=296$, cf. Figure 3); children of this group are labeled 'pre-treated'.

Figure 3 Study design

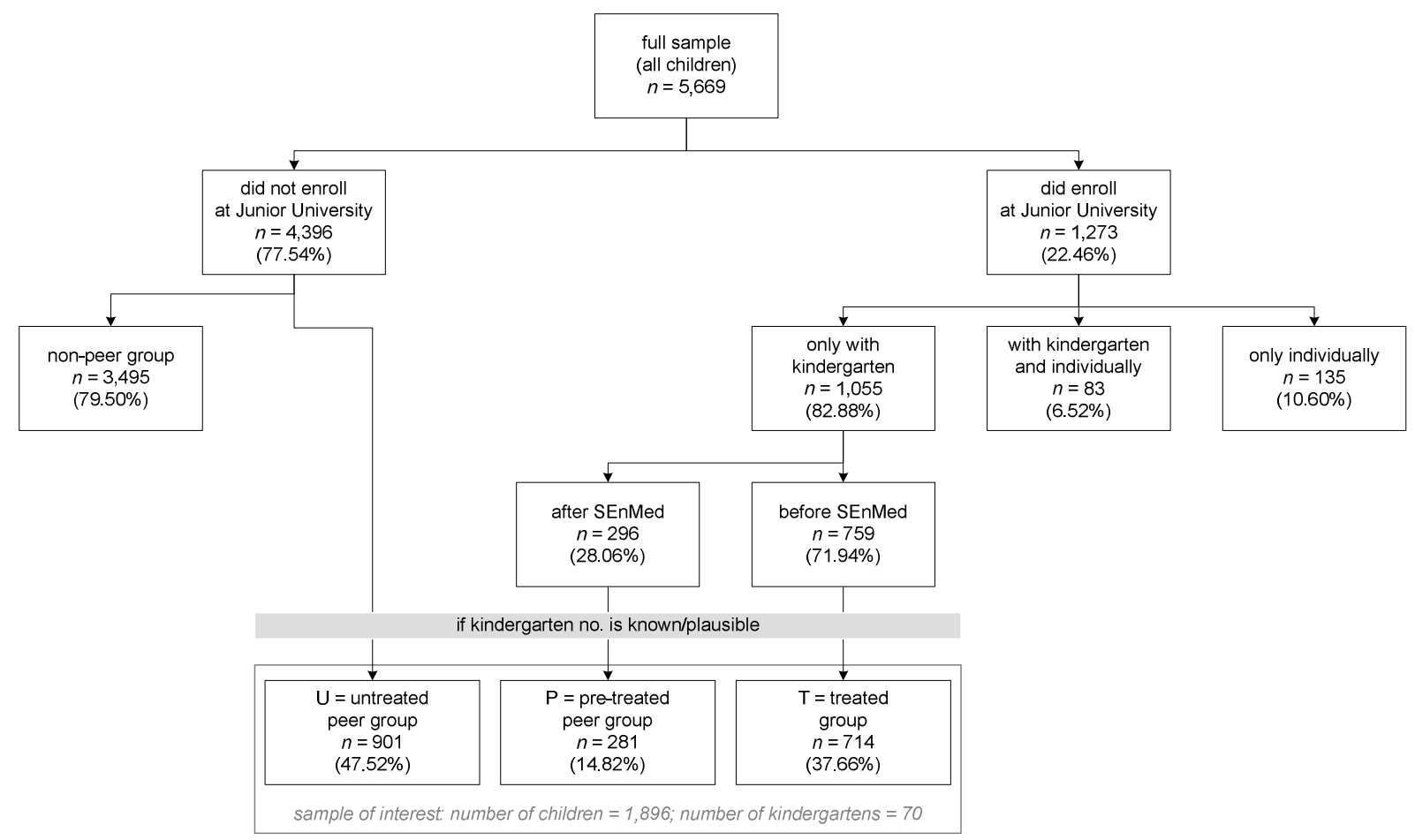

Selectivity in kindergarten entry due to JU participation is not an issue for either group of children. The children in the sample entered kindergarten about two years before JU was launched. Hence, there is no self-selection of children in kindergartens or preschool classes due to expected JU participation. Even if parents want their children to enroll at JU, it is unlikely that they will change kindergarten solely for this purpose. First, even if the kindergarten does not participate in JU, the individual child can be enrolled for JU classes anyway. Second, to change kindergarten might not be an option for families. In Wuppertal, as in many other German cities, there is a shortage of daycare. Parents have to apply for daycare 
very early, i.e. one or two years before their child's third birthday. In addition, changing kindergarten requires convincing arguments and may as well involve other opportunity costs, such as a greater distance between home and the new kindergarten.

Besides selectivity issues regarding participating and non-participating kindergartens, potential selectivity into the treatment, pre-treatment or control group within a kindergarten needs to be addressed. To support the exogeneity of the treatment assumption, we perform mean comparison tests for the control variables and all groups of children. As our sample ( $n=1,896$, cf. Figure 3 ) includes children from 70 kindergartens ${ }^{10}$, we calculate clustered tests. As noted in Section 2, Wuppertal is segregated and this is also reflected in kindergarten segregation. Thus, observations within kindergartens are likely to be correlated and standard $\chi^{2}$-tests or t-tests for the control variables are likely to be upward biased (and $p$-values are likely to be downward biased). Hence, we calculate kindergarten cluster-adjusted tests as described in Donner/Klar (2000). Table 2 presents the results of mean comparison tests, where the sample is restricted to children with non-missing values in the explanatory variables. $^{11}$

\footnotetext{
${ }^{10} 14$ of 84 kindergartens were eliminated from the analysis as only one participant or non-participant in the two cohorts could be merged to the SEnMed data. This mainly results from incorrect entries of the kindergarten number by the physicians or assistants during the SEnMed and is uncorrelated with treatment status.

${ }^{11}$ As noted in footnote 10 , missing values are uncorrelated with the treatment status and occur at random. A large set of missing values results from incorrect entries (implausible coding) by the physicians or assistants during the SEnMed.
} 
Table 2 Descriptive statistics by treatment, non-treatment, pre-treatment group

\begin{tabular}{|c|c|c|c|c|c|c|}
\hline & \multicolumn{2}{|c|}{$\overline{(1)}$} & \multicolumn{2}{|c|}{$\overline{(2)}$} & \multicolumn{2}{|c|}{ (3) } \\
\hline & \multicolumn{2}{|c|}{$\begin{array}{l}\text { Non-treatment }(\mathrm{U}) \text { vs. } \\
\text { treatment }(\mathrm{T})\end{array}$} & \multicolumn{2}{|c|}{$\begin{array}{l}\text { Pre-treatment }(\mathrm{P}) \\
\text { vs. treatment }(\mathrm{T})\end{array}$} & \multicolumn{2}{|c|}{$\begin{array}{l}\text { Non-treatment }(\mathrm{U}) \\
\text { vs. Pre-treatment }(\mathrm{P})\end{array}$} \\
\hline & $\mathrm{U}$ & $\mathrm{T}$ & $\mathrm{P}$ & $\mathrm{T}$ & $\mathrm{U}$ & $\mathrm{P}$ \\
\hline Sample size & 788 & 664 & 236 & 664 & 788 & 236 \\
\hline Average age at examination & $\begin{array}{c}5.94 \\
(0.0091)\end{array}$ & $\begin{array}{c}5.96 \\
(0.0095)\end{array}$ & $\begin{array}{c}5.94 \\
(0.0164)\end{array}$ & $\begin{array}{c}5.96 \\
(0.0095)\end{array}$ & $\begin{array}{c}5.94 \\
(0.0095)\end{array}$ & $\begin{array}{c}5.94 \\
(0.0167)\end{array}$ \\
\hline$\%$ boys & 51.40 & 46.23 & 50.85 & 46.23 & 51.40 & 50.85 \\
\hline$\%$ with migration background & 37.18 & 36.30 & 39.41 & 36.30 & 37.18 & 39.41 \\
\hline Average time in kindergarten (in years) & $\begin{array}{c}2.81 \\
(0.0457)\end{array}$ & $\begin{array}{c}2.87 \\
(0.0462)\end{array}$ & $\begin{array}{c}2.76 \\
(0.0879)\end{array}$ & $\begin{array}{c}2.87 \\
(0.0507)\end{array}$ & $\begin{array}{c}2.81 \\
(0.0418)\end{array}$ & $\begin{array}{c}2.76 \\
(0.0712)\end{array}$ \\
\hline Number of siblings in $\%$ & $\begin{array}{c}21.19 \\
45.05 \\
21.57 \\
7.74 \\
4.44 \\
\end{array}$ & $\begin{array}{c}23.80 \\
50.15 \\
18.22 \\
5.27 \\
2.56 \\
\end{array}$ & $\begin{array}{c}22.46 \\
48.73 \\
20.34 \\
5.93 \\
2.54 \\
\end{array}$ & $\begin{array}{c}23.80 \\
50.15 \\
18.22 \\
5.27 \\
2.56 \\
\end{array}$ & $\begin{array}{c}21.19 \\
45.05 \\
21.57 \\
7.74 \\
4.44 \\
\end{array}$ & $\begin{array}{c}22.46 \\
48.73 \\
20.34 \\
5.93 \\
2.54 \\
\end{array}$ \\
\hline 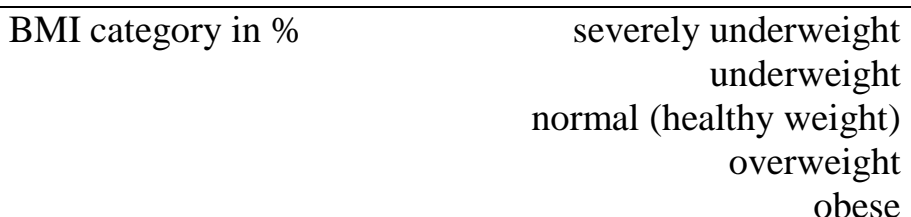 & $\begin{array}{c}2.66 \\
7.49 \\
78.68 \\
6.09 \\
5.08\end{array}$ & $\begin{array}{c}2.11 \\
6.02 \\
79.97 \\
7.68 \\
4.22\end{array}$ & $\begin{array}{c}3.81 \\
8.05 \\
76.69 \\
7.20 \\
4.24\end{array}$ & $\begin{array}{c}2.11 \\
6.02 \\
79.97 \\
7.68 \\
4.22\end{array}$ & $\begin{array}{c}2.66 \\
7.49 \\
78.68 \\
6.09 \\
5.08\end{array}$ & $\begin{array}{c}3.81 \\
8.05 \\
76.69 \\
7.20 \\
4.24\end{array}$ \\
\hline$\%$ low birth weight & 7.49 & 6.17 & 8.47 & 6.17 & 7.49 & 8.47 \\
\hline$\%$ health record presented & 97.08 & 96.39 & 95.34 & 96.39 & 97.08 & 95.34 \\
\hline$\%$ with U7a (medical screening at age 34-36 months) & 89.97 & 89.46 & 89.83 & 89.46 & 89.97 & 89.83 \\
\hline$\%$ vaccination record presented & 95.94 & 95.03 & 93.64 & 95.03 & 95.94 & 93.64 \\
\hline$\%$ with tetanus vaccination & 95.30 & 94.28 & 92.80 & 94.28 & 95.30 & 92.80 \\
\hline$\%$ reduced visual acuity & 22.34 & 19.58 & 18.22 & 19.58 & 22.34 & 18.22 \\
\hline$\%$ partial hearing loss & 7.61 & 6.02 & 8.90 & 6.02 & 7.61 & 8.90 \\
\hline$\%$ with behavioral problems & 5.71 & 4.97 & 4.24 & 4.97 & 5.71 & 4.24 \\
\hline $\begin{array}{l}\text { Average } \% \text { of welfare dependent households } \\
\text { payments with children per city block }\end{array}$ & $\begin{array}{c}29.24 \\
(1.5357)\end{array}$ & $\begin{array}{c}29.48 \\
(1.5451)\end{array}$ & $\begin{array}{c}31.55 \\
(2.4251)\end{array}$ & $\begin{array}{c}29.48 \\
(1.4038)\end{array}$ & $\begin{array}{c}29.24 \\
(1.3550)\end{array}$ & $\begin{array}{c}31.55 \\
(2.2902)\end{array}$ \\
\hline $\begin{array}{l}\text { Average } \% \text { of immigrant children } \\
(<6 \text { years) per city block }\end{array}$ & $\begin{array}{c}52.91 \\
(3.4729)\end{array}$ & $\begin{array}{c}49.57 \\
(3.4277)\end{array}$ & $\begin{array}{c}53.43 \\
(5.0795)\end{array}$ & $\begin{array}{c}49.57 \\
(2.9100)\end{array}$ & $\begin{array}{c}52.91 \\
(3.2141)\end{array}$ & $\begin{array}{c}53.43 \\
(5.4254)\end{array}$ \\
\hline $\begin{array}{l}\text { Average disposable income (in } \\
€ 10,000) \text { in postal code area }\end{array}$ & $\begin{array}{c}3.88 \\
(0.1359)\end{array}$ & $\begin{array}{c}3.98 \\
(0.1337)\end{array}$ & $\begin{array}{c}3.87 \\
(0.1946)\end{array}$ & $\begin{array}{c}3.98 \\
(0.1112)\end{array}$ & $\begin{array}{c}3.88 \\
(0.1222)\end{array}$ & $\begin{array}{c}3.87 \\
(0.2000)\end{array}$ \\
\hline
\end{tabular}

Notes: Bold figures indicate significant differences between groups $(p \leq 0.05)$ based on clustered t-tests (for age, kindergarten, city block and postal code information) and clustered $\chi^{2}$-tests (for the other variables); cluster-adjusted standard errors in parentheses; cluster variable is kindergarten. 
As shown in Table 2, with the exception of the gender variable, there are no significant differences between the control group (children not enrolled at JU), the treatment group (children examined in the SEnMed after enrolling at JU) or the pre-treatment group (children examined in the SEnMed before enrolling at JU). While boys are overrepresented when looking at overall enrollments at JU (about $70 \%$ of participants are boys), we expect the average allocation of boys and girls in the kindergarten groups to reflect the percentage of boys and girls in the kindergarten population in Wuppertal, i.e. about $51 \%$ boys and $49 \%$ girls. Since there is no obvious explanation for the difference (cf. Table 2, column (1)) and the distribution of boys and girls in the kindergartens in Wuppertal is not equal, we control for gender and for possible group specific treatment effects in the regressions.

Differences in other variables between treated and the pre-treated children (Table 2, column (2)) and treated and non-treated children (Table 2, column (1)) are not statistically significant. While not significant, the differences might still suggest that pre-treated and nontreated children are from less advantaged backgrounds. The children tend to have a lower birth weight and to live in neighborhoods with higher immigrant ratios. But none of these significant or insignificant differences threatens our identification strategy. In the following, we show that JU attendance and the date of SEnMed - which may determine group assignment (treated or pre-treated) - do not depend on those variables (the kindergarten decides whether to participate in JU but not on the date of the child's SEnMed). Therefore, $\mathrm{JU}$ attendance is exogenous. Nevertheless, in our models we control for the socioeconomic background and for possible non-linear and indirect effects. We also perform different robustness checks using matching methods to further support the exogeneity assumption.

While the treatment depends only on the decision of the kindergarten teacher to enroll at JU and not on the children's observed characteristics, different preschool classes within a kindergarten might be taught by different teachers of different quality. This might 
affect both the decision to attend JU courses as well as the child's performance on the test. Therefore, participation within a kindergarten might not be purely random and high ability groups with motivated teachers may be more likely to participate in JU courses. Hence, there might be unobserved heterogeneity due to teacher characteristics. This creates yet another identification challenge: We have to rule out that the treatment effect reflects the unobserved quality of the preschool teacher. As we have no information on preschool teachers, we cannot tell whether different preschool classes are taught by the same person, let alone what that person's quality as an educator may be. Nevertheless, this does not threaten our identification strategy for the following reason: A preschool class with pre-treated and treated children is taught by the same teacher. Hence, if assignment to one of these groups is random and JU attendance increases school readiness, children in the treatment group are expected to show higher school readiness than their pre-treated peers. For this approach to be valid, we have to ensure that being allocated to the treated or pre-treated group is in fact random.

In Wuppertal, unlike in other municipalities, invitation to SEnMed depends solely on date of birth. Thus, it is only the date of birth which determines assignment to the pretreatment or treatment group. The date of the SEnMed does not depend on the kindergarten, family name, prospective school catchment area or district of residence. SEnMed is therefore exogenous with respect to all other (observed or unobserved) individual, family or even kindergarten characteristics. Parents are notified of the upcoming SEnMed about 3-4 weeks before the scheduled SEnMed date. Consequently, children of the same age (between 5 years, 10 months and 6 years) will undergo the examination throughout the year. However, children in JU classes are not sorted according to age. Thus, children within a single preschool class both before and after conducted SEnMed participate in the same JU course. Within this group, older children are more likely to be examined before attending JU and 
therefore to be allocated to the pre-treatment group. To rule out sorting into the pre-treatment group and maturity effects in this context, we have to ensure that the age distribution in all comparison groups taking the SEnMed does in fact not differ systematically. Small differences in age at SEnMed occur because some families might miss the appointment or have time constraints and their children take the SEnMed later than scheduled. To verify the exogeneity assumption of the treatment, we calculate the difference in months between the theoretical SEnMed date without any sorting (where children are on average 5 years and 11 months old) and the observed SEnMed date. We conduct mean comparison tests on the difference $(\triangle S E n M e d)$ for the treated and pre-treated children. If the exogeneity assumption holds, there should be no differences in $\triangle S E n M e d$.

Table 3 reports the mean comparison test for the difference in theoretical and observed SEnMed date in months ( $\triangle S E n M e d)$. It turns out that parents of pre-treated children are not more likely to defer their child's SEnMed than parents of treated children. ${ }^{12}$ Hence, children in both groups are equally likely to be treated before or after SEnMed; there is no selectivity. Moreover, note that there are no significant differences either in age or in average time in kindergarten (cf. Table 2, column (2)) between either group, which supports the exogeneity assumption and the identification strategy. Hence, the pre-treatment group is not a selective group; neither of all children nor of the treated children.

\footnotetext{
${ }^{12} 35$ Children (13 from the pre-treatment group, 22 from the treatment group) are excluded from this analysis, because they are either too old (possibly due to migration) or too young (due to early enrollment) to be in the cohort.
} 
Table 3 Mean comparison test for difference between theoretical and observed SEnMed date, treatment vs. pre-treatment group

\begin{tabular}{|c|c|c|c|c|}
\hline Group & $\bar{n}$ & Mean $\triangle S E n M e d$ & Std. Err. & Std. Dev. \\
\hline Treatment & 642 & 0.7181 & 0.0544 & 1.3784 \\
\hline Pre-Treatment & 223 & 0.6906 & 0.0811 & 1.2112 \\
\hline Combined & 865 & 0.7110 & 0.0450 & 1.3885 \\
\hline Difference & & -0.0275 & 0.1040 & \\
\hline$H_{0}:$ Difference $=0$ & $t$-value & -0.2644 & $p$-value & 0.7915 \\
\hline
\end{tabular}

Note: Standard t-tests, not clustered.

\subsection{Estimation approach}

To analyze the effect of JU attendance, we use 'school readiness' as introduced in Section 3.1 (cf. Figure 1) as our dependent variable. The effect is estimated using a fixed effects model in which we explain school readiness by a dummy representing JU participation $(J U$; $1=$ treatment, $0=$ non-treatment), individual level information, and the regional controls discussed above (cf. Section 3.2). The model is

$$
y_{i c k}=\alpha+\beta X_{i c k}+\gamma J U_{i c k}+\mu_{k}+\lambda_{c}+\varepsilon_{i c k}
$$

where $y_{i c k}$ represents the school readiness of child $i$ of cohort $c$ in preschool $k . X_{i c k}$ are background characteristics (e.g. dummy for being a boy), and $J U_{i c k}$ is the dummy indicating that the child attended JU courses with the preschool class before taking the SEnMed. $\mu_{k}$ reflects unobserved time-invariant preschool characteristics, including shared preferences of parents and kindergarten quality. $\lambda_{c}$ captures SEnMed-cohort specific characteristics, and $\varepsilon_{i c k}$ is the individual error term.

Although we have argued that JU attendance is exogenous with respect to kindergarten and the controls, our model and data may still suffer from a lack of relevant individual-level information which affect school readiness. This applies in particular to the socioeconomic status of the families. To account for these background characteristics, we include information on the city block level and income information on a postal code basis. 
The individual controls used in the estimation are taken from SEnMed. Thus the data, in particular the data of the treatment group, were collected post-treatment. Time-invariant or pre-treatment variables like gender, immigration status or birth weight are clearly not affected. Most variables from the SEnMed are exogenous to the treatment (like number of siblings or obesity) and are included in equation (1). Other information, however, is not included, because the variables are endogenous either to other exogenous variables or to the outcome, e.g. recommendations to out-patient treatment based on the test results.

To support our identification strategy, we estimate the effect of JU attendance using different groups. First, we estimate equation (1) using data on pre-treated and treated children only. If $\mathrm{JU}$ attendance has a causal impact on school readiness, children in the treatment group should have significantly higher school readiness compared to pre-treated children. School readiness of the pre-treatment group cannot be affected by JU attendance, as the group took the SEnMed before attending JU. Second, we compare pre-treated children with non-treated children. As the pre-treatment group is made up of children who attended JU with their preschool class after they took the SEnMed, we do not expect a significant effect from JU treatment. If, however, we estimate a significant coefficient for the JU dummy, the treatment is more likely to capture unobserved individual, family or kindergarten characteristics, rather than the causal effect of JU attendance on school readiness. Hence, a significant coefficient would raise doubts about our identification strategy.

\subsection{Robustness check}

To further check the robustness of our approach, we compare the results from the regressions described in Section 4.2 with results of a matching estimator. As discussed in Section 4.1, there are differences in some exogenous variables between the defined groups, though 
almost all of these differences are statistically insignificant. To rule out any selectivity problem latent in these differences that might bias our estimated JU effect, we estimate the average treatment effect on the treated using different propensity score matching methods.

\section{Results}

\subsection{Junior University effect}

Table 4 summarizes the regression results. The result of the basic model is reported in column (1).

The model is estimated by OLS and includes kindergarten and SEnMed-cohort fixed effects. We regress school readiness on the treatment dummy (JU participation, $1=$ treatment $/ 0=$ non-treatment $)$, a gender dummy (male=1) and a dummy for immigrant status (immigrant=1/native $=0$ ). In addition, we control for linear age and kindergarten duration effects. The latter variable describes whether duration in kindergarten exceeds or is below the theoretical duration (time between the child's third birthday and the SEnMed). As the dependent variable is standardized between 0 and 100, the effects of all variables can be interpreted as changes in school readiness in percentage points.

In the first model the JU treatment variable is positive and statistically significant. Children attending JU courses with their preschool class perform better than their kindergarten peers who did not enroll at JU. The additional achievement of 2.33 percentage points corresponds to about three (of 129) additional tasks completed at SEnMed. The negative coefficients for boys and immigrants are both statistically significant and plausible. Girls and native Germans tend to perform better. In addition, we observe a significant age effect of about $0.54 \%$ per month. 
Table 4 Junior University effect on school readiness, treatment vs. control (non-treatment) group

\begin{tabular}{|c|c|c|c|c|}
\hline & $(1)$ & $(2)$ & $(3)$ & $(4)$ \\
\hline Junior University treatment $($ yes $=1 /$ no $=0$ ) & $\begin{array}{l}2.3259^{* * *} \\
(0.6534)\end{array}$ & $\begin{array}{l}2.2811^{* * *} \\
(0.5524)\end{array}$ & $\begin{array}{l}2.1743^{* * *} \\
(0.5449)\end{array}$ & $\begin{array}{l}2.1835^{* * *} \\
(0.5634)\end{array}$ \\
\hline Gender $($ male $=1)$ & $\begin{array}{c}-2.5206^{* * *} \\
(0.4514)\end{array}$ & $\begin{array}{c}-1.8849^{* * *} \\
(0.4199)\end{array}$ & $\begin{array}{c}-1.9918^{* * *} \\
(0.4332)\end{array}$ & $\begin{array}{c}-2.0641^{* * * *} \\
(0.4514)\end{array}$ \\
\hline Immigrant $($ yes $=1)$ & $\begin{array}{c}-4.9335^{* * *} \\
(0.7561)\end{array}$ & $\begin{array}{c}-4.4872^{* * *} \\
(0.7707)\end{array}$ & $\begin{array}{c}-4.2814^{* * *} \\
(0.7311)\end{array}$ & $\begin{array}{c}-4.3321^{\text {*** }} \\
(0.9666)\end{array}$ \\
\hline Age (in months) & $\begin{array}{l}0.5361^{* * *} \\
(0.1297)\end{array}$ & $\begin{array}{c}0.4857^{* * *} \\
(0.1125)\end{array}$ & $\begin{array}{l}0.4965^{* * *} \\
(0.1154)\end{array}$ & $\begin{array}{c}0.4907^{* * *} \\
(0.1151)\end{array}$ \\
\hline Constant & $\begin{array}{c}45.3271^{* * *} \\
(9.4242)\end{array}$ & $\begin{array}{c}43.2431^{* * *} \\
(8.6889)\end{array}$ & $\begin{array}{l}-23.7941 \\
(91.9862)\end{array}$ & $\begin{array}{l}-21.6346 \\
(91.7319)\end{array}$ \\
\hline Cohort fixed effects & $\checkmark$ & $\checkmark$ & $\checkmark$ & $\checkmark$ \\
\hline Kindergarten fixed effects & $\checkmark$ & $\checkmark$ & $\checkmark$ & $\checkmark$ \\
\hline $\begin{array}{l}\text { Kindergarten duration below/exceeds three } \\
\text { years (in months) }\end{array}$ & $\checkmark$ & $\checkmark$ & $\checkmark$ & $\checkmark$ \\
\hline Number of siblings & & $\checkmark$ & $\checkmark$ & $\checkmark$ \\
\hline Health status & & $\checkmark$ & $\checkmark$ & $\checkmark$ \\
\hline City block information & & $\checkmark$ & & \\
\hline Disposable income in postal code area & & $\checkmark$ & $\checkmark$ & $\checkmark$ \\
\hline SES index (city block) & & & $\checkmark$ & $\checkmark$ \\
\hline $\begin{array}{l}\text { Kindergarten, SES index, and disposable } \\
\text { income polynomials }\end{array}$ & & & $\checkmark$ & $\checkmark$ \\
\hline $\begin{array}{l}\text { Gender, immigrant and kindergarten duration } \\
\text { interactions }\end{array}$ & & & & $\checkmark$ \\
\hline Observations & 1,452 & 1,452 & 1,452 & 1,452 \\
\hline Kindergartens & 70 & 70 & 70 & 70 \\
\hline$R^{2}$ & 0.2667 & 0.3612 & 0.3705 & 0.3703 \\
\hline Adjusted $R^{2}$ & 0.2268 & 0.3175 & 0.3219 & 0.3216 \\
\hline
\end{tabular}

Notes: OLS estimates with kindergarten and cohort fixed effects; dependent variable is school readiness score; standard errors in parentheses are clustered at the kindergarten level; ${ }^{+} p<0.10,{ }^{* *} p<0.05,{ }^{* * *} p<0.01$; explanatory variables: health status: low birth weight, obesity/overweight, (severe) underweight, nonpresentation of health record, U7a medical screening conducted, non-presentation of vaccination record, tetanus vaccination, reduced visual acuity, partial hearing loss, and behavioral problems; city block information: share of welfare dependent households with children and the share of immigrant children below the age of six; SES index is the index of socio economic status and includes the following variables: share of immigrants, share of immigrant children under the age of six, employment share, unemployment share, share of welfare recipients, share of welfare dependent households with children and share of unemployable adults; polynomials include second, third and fourth order polynomials of Kindergarten duration below/exceeds three years (in months), SES index, and disposable income; interactions: gender and immigrant status, kindergarten duration below/exceeds three years (in months) and immigrant status, kindergarten duration below/exceeds three years (in months) and gender.

Nevertheless, there are some other variables not included in (1) which may also affect school readiness and have to be controlled. Therefore, we add additional controls and estimate 
different specifications, like non-linear effects and interaction terms. In model (2) we include the number of siblings, information on health status like low birth weight, obesity/overweight, (severe) underweight, non-presentation of health record, U7a conducted (a medical screening conducted at the age of 34 to 36 months), non-presentation of vaccination record, tetanus vaccination, reduced visual acuity, partial hearing loss, and behavioral problems. The model also includes socioeconomic information on the city block and postal code area level. The city block information includes the share of households with children receiving welfare payments and the share of immigrant children below the age of six. The postal code information is the average annual disposable income per household (in ten thousand Euros). In this second model, the estimated treatment effect drops only slightly to 2.28 and remains highly significant. In model (3) we exclude city block information and generate an index for low economic and social status from the city block data. The index comprises the following variables weighted by principal factor analysis: share of immigrants, share of immigrant children under the age of six, employment share for employees with monthly income above $€ 400$, unemployment share, share of welfare recipients, share of households with children receiving welfare and share of unemployable adults. To control for non-linear effects, we include second, third and fourth order polynomials of kindergarten duration, city block social status index and average disposable income in model (3). The results are similar to those of model (2). In model (4) we also add interactions of gender with immigrant status, kindergarten duration with immigrant status, and kindergarten duration with gender. ${ }^{13}$ However, the results of models (2) to (4) show a robust and significant JU effect. In model (4) the JU effect of 2.18 percentage points still amounts to 2.82 additional tasks completed, corresponding to about $1 / 5$ of a standard deviation in the total score. Put

\footnotetext{
${ }^{13}$ In further specifications, not reported here, we allow for non-linear age effects and group specific age effects. Neither the results nor the marginal age effect change considerably.
} 
differently: Gains in ability from attending JU classes corresponds to an age effect of 4.4 months. ${ }^{14}$

As discussed in Section 3.1, the SEnMed data does not include information on preschool teacher quality. However, teacher quality is an important predictor of educational success. Hence, it may turn out that our models suffer from an omitted variable bias. Exploiting our study-design, we can compare different groups of children (treated and pretreated) which are taught by the same teacher and further check the validity of the results presented in Table 4. As our final robustness check we apply propensity score matching.

First, as introduced in Section 4.2, we compare the treatment and the control group to the pre-treatment group. When comparing the treated to the pre-treated children, we expect non-zero JU coefficients similar to the coefficients in Table 4, provided the model is correctly specified and JU attendance is exogenous. Second, when comparing the control group (non-treatment) with the pre-treatment group, the JU coefficient should be zero. If these hypotheses are confirmed, this supports our identification strategy.

The results using the treated and pre-treated children are presented in Table 5. Results for pre-treated vs. non-treated children are given in Table 6.

Our first hypothesis for the pre-treatment and treatment group - JU coefficient not equal to zero and similar to that of Table 4 - is confirmed. Only children who attend JU before taking their SEnMed show higher school readiness. Hence, the better performance of the treated is not explained by selectivity because the pre-treatment group participates in JU only after school readiness has already been assessed. As argued in Section 4 (Table 2), pretreated children are not a selective group of all children. The children are similar with respect to the relevant variables and there are no age effects which might explain short-term

\footnotetext{
${ }^{14}$ Since boys are underrepresented in preschool classes at JU (cf. Section 4.1), we checked for group specific effects of JU attendance and find no significant differences in JU effect for boys and girls. Both groups benefit equally from attending JU classes.
} 
differences in school readiness (cf. Section 4.1). Hence, we can rule out selectivity issues that arise from the preschool teacher quality. Both groups, treatment and pre-treatment group, have the same preschool teacher but show different results on the school entrance test. If the ability measured at SEnMed is only caused by the quality of the teacher, the treatment effect should be zero. Hence, our results suggest that JU attendance causes significantly higher outcomes at SEnMed. Note that not only the coefficients for the treatment variable are similar to the coefficients in Table 4; the $R^{2}$ 's are similar as well.

Table 5 Junior University effect on school readiness, treatment vs. pre-treatment group

\begin{tabular}{|c|c|c|c|c|}
\hline & $(1)$ & $(2)$ & (3) & $(4)$ \\
\hline $\begin{array}{l}\text { Junior University treatment } \\
(\text { yes }=1 / \text { pre-treatment }=0)\end{array}$ & $\begin{array}{l}3.1104^{* * *} \\
(1.1073)\end{array}$ & $\begin{array}{l}2.8973^{* * *} \\
(1.0416)\end{array}$ & $\begin{array}{l}2.7413^{* * * *} \\
(1.0204)\end{array}$ & $\begin{array}{l}2.6945^{* * *} \\
(1.0058)\end{array}$ \\
\hline Gender $($ male $=1)$ & $\begin{array}{c}-2.4255^{* * *} \\
(0.7130)\end{array}$ & $\begin{array}{c}-1.9161^{* * *} \\
(0.6194)\end{array}$ & $\begin{array}{c}-2.0722^{* * *} \\
(0.6321)\end{array}$ & $\begin{array}{c}-2.5587^{* * *} \\
(0.8012)\end{array}$ \\
\hline Immigrant (yes = 1) & $\begin{array}{c}-4.8482^{* * *} \\
(1.0736)\end{array}$ & $\begin{array}{c}-3.8469^{* * *} \\
(1.0602)\end{array}$ & $\begin{array}{c}-4.0303^{* * *} \\
(1.0274)\end{array}$ & $\begin{array}{c}-4.4513^{* * *} \\
(1.1638)\end{array}$ \\
\hline Age (in months) & $\begin{array}{l}0.4813^{+} \\
(0.2505)\end{array}$ & $\begin{array}{l}0.4922^{* *} \\
(0.2005)\end{array}$ & $\begin{array}{l}0.5256^{* * *} \\
(0.1969)\end{array}$ & $\begin{array}{l}0.5264^{* *} \\
(0.1991)\end{array}$ \\
\hline Constant & $\begin{array}{l}48.0470^{* *} \\
(18.3704)\end{array}$ & $\begin{array}{l}41.9492^{* *} \\
(16.5776)\end{array}$ & $\begin{array}{l}-110.2123 \\
(104.7102) \\
\end{array}$ & $\begin{array}{l}-101.8509 \\
(107.4184)\end{array}$ \\
\hline Cohort fixed effects & $\checkmark$ & $\checkmark$ & $\checkmark$ & $\checkmark$ \\
\hline Kindergarten fixed effects & $\checkmark$ & $\checkmark$ & $\checkmark$ & $\checkmark$ \\
\hline $\begin{array}{l}\text { Kindergarten duration below/exceeds three } \\
\text { years (in months) }\end{array}$ & $\checkmark$ & $\checkmark$ & $\checkmark$ & $\checkmark$ \\
\hline Number of siblings & & $\checkmark$ & $\checkmark$ & $\checkmark$ \\
\hline Health status & & $\checkmark$ & $\checkmark$ & $\checkmark$ \\
\hline City block information & & $\checkmark$ & & \\
\hline Disposable income in postal code area & & $\checkmark$ & $\checkmark$ & $\checkmark$ \\
\hline SES index (city block) & & & $\checkmark$ & $\checkmark$ \\
\hline $\begin{array}{l}\text { Kindergarten, age, SES index, and } \\
\text { disposable income polynomials }\end{array}$ & & & $\checkmark$ & $\checkmark$ \\
\hline $\begin{array}{l}\text { Age, gender, immigrant and kindergarten } \\
\text { duration interactions }\end{array}$ & & & & $\checkmark$ \\
\hline Observations & 900 & 900 & 900 & 900 \\
\hline Kindergartens & 70 & 70 & 70 & 70 \\
\hline$R^{2}$ & 0.2918 & 0.3748 & 0.3930 & 0.3905 \\
\hline Adjusted $R^{2}$ & 0.2273 & 0.3026 & 0.3144 & 0.3107 \\
\hline
\end{tabular}

Notes: see Table 4. 
Table 6 summarizes the results of the comparison of pre-treated and non-treated children. Again, our hypothesis is confirmed. The JU coefficient does not statistically differ from zero at any significance level and regardless of the specification. The coefficients of the other variables, their significance levels, as well as the $R^{2}$ 's are similar to the model specifications in Tables 4 and 5.

Table 6 Junior University effect on school readiness, pre-treatment vs. control (nontreatment) group

\begin{tabular}{|c|c|c|c|c|}
\hline & $(1)$ & (2) & (3) & (4) \\
\hline $\begin{array}{l}\text { Junior University treatment } \\
\text { (pre-treatment }=1 / \mathrm{no}=0)\end{array}$ & $\begin{array}{l}-0.8221 \\
(1.0341)\end{array}$ & $\begin{array}{l}-0.7553 \\
(0.9441)\end{array}$ & $\begin{array}{l}-0.7641 \\
(0.9587)\end{array}$ & $\begin{array}{l}-0.7191 \\
(0.9590)\end{array}$ \\
\hline Gender $($ male $=1)$ & $\begin{array}{c}-2.4958^{* * *} \\
(0.5706)\end{array}$ & $\begin{array}{c}-1.8862^{* * *} \\
(0.5299)\end{array}$ & $\begin{array}{c}-1.9869^{* * *} \\
(0.5445)\end{array}$ & $\begin{array}{c}-2.1523^{* * *} \\
(0.5999)\end{array}$ \\
\hline Immigrant $($ yes $=1)$ & $\begin{array}{l}-4.4143^{* * *} \\
(0.8594)\end{array}$ & $\begin{array}{l}-3.6150^{* * *} \\
(0.8567)\end{array}$ & $\begin{array}{c}-3.4857^{* * *} \\
(0.7801)\end{array}$ & $\begin{array}{l}-2.8078^{* *} \\
(1.1724)\end{array}$ \\
\hline Age (in months) & $\begin{array}{l}0.6640^{* * *} \\
(0.1924)\end{array}$ & $\begin{array}{l}0.5898^{* * *} \\
(0.1705)\end{array}$ & $\begin{array}{c}0.5750^{* * *} \\
(0.1701)\end{array}$ & $\begin{array}{c}0.5872^{* * *} \\
(0.1713)\end{array}$ \\
\hline Constant & $\begin{array}{l}35.5022^{* *} \\
(13.7925)\end{array}$ & $\begin{array}{l}32.5434^{* *} \\
(13.8295)\end{array}$ & $\begin{array}{l}-197.2360 \\
(145.3927)\end{array}$ & $\begin{array}{l}-190.3469 \\
(146.9110)\end{array}$ \\
\hline Cohort fixed effects & $\checkmark$ & $\checkmark$ & $\checkmark$ & $\checkmark$ \\
\hline Kindergarten fixed effects & $\checkmark$ & $\checkmark$ & $\checkmark$ & $\checkmark$ \\
\hline $\begin{array}{l}\text { Kindergarten duration below/exceeds three } \\
\text { years (in months) }\end{array}$ & $\checkmark$ & $\checkmark$ & $\checkmark$ & $\checkmark$ \\
\hline Number of siblings & & $\checkmark$ & $\checkmark$ & $\checkmark$ \\
\hline Health status & & $\checkmark$ & $\checkmark$ & $\checkmark$ \\
\hline City block information & & $\checkmark$ & & \\
\hline Disposable income in postal code area & & $\checkmark$ & $\checkmark$ & $\checkmark$ \\
\hline SES index (city block) & & & $\checkmark$ & $\checkmark$ \\
\hline $\begin{array}{l}\text { Kindergarten, age, SES index, and } \\
\text { disposable income polynomials }\end{array}$ & & & $\checkmark$ & $\checkmark$ \\
\hline $\begin{array}{l}\text { Age, gender, immigrant and kindergarten } \\
\text { duration interactions }\end{array}$ & & & & $\checkmark$ \\
\hline Observations & 1,024 & 1,024 & 1,024 & 1,024 \\
\hline Kindergartens & 70 & 70 & 70 & 70 \\
\hline$R^{2}$ & 0.2815 & 0.3862 & 0.3986 & 0.3993 \\
\hline Adjusted $R^{2}$ & 0.2246 & 0.3248 & 0.3312 & 0.3313 \\
\hline
\end{tabular}

Notes: see Table 4. 


\subsection{Robustness check}

As discussed in Section 4 there are some statistically insignificant but possibly nonnegligible differences in the control variables between pre-treated and treated children and between non-treated and treated children. Hence, as a robustness check, we estimate the average treatment effect of the treated (ATT) using propensity score matching. We use model (4) (Tables 4, 5, and 6) and different specifications of the matching estimator to account for the variance/bias trade-off. Table 7 summarizes the results for all groups.

The matching results for the main comparison group (treated vs. control) differ according to the varying specifications of the $k$-nearest neighbor algorithm with up to three neighbors and different number of observations on support. However, results are qualitatively similar and, in addition, similar to the results in Table 4. Only the ATT in the most restrictive specifications (Table 7, columns 1 and 4) is lowest and the estimated effect is only marginally significant. However, note that model (4) is saturated with various polynomials and interaction effects and finding statistical twins is not easy, especially when applying rather strict requirements like in Table 7 column (1). Therefore, relaxing the requirements on the fit by e.g. raising or eliminating the caliper, leads to results similar to those in the regression analysis.

The results for the pre-treatment and the control groups are qualitatively similar to the results in Table 6 . Hence, there is no difference in school readiness between untreated and pre-treated children. This supports our exogeneity assumption. Applying matching to the pre-treated and treated children gives slightly different results. The variation in the different ATT specifications (with or without caliper, value of caliper, with or without neighbors) is higher than for the other group comparisons and the treatment effect is slightly stronger than in the regression results. Overall, however, the matching results do not differ qualitatively from the OLS results in neither specification and hence confirm our main specification. 
Table 7 Matching results, $k$-nearest neighbor matching with varying specifications

\begin{tabular}{|c|c|c|c|c|c|c|c|}
\hline \multirow[b]{2}{*}{$\begin{array}{l}\text { Groups and } \\
\text { treatment status }\end{array}$} & & $(1)$ & $(2)$ & $(3)$ & $(4)$ & $(5)$ & $(6)$ \\
\hline & $\begin{array}{r}\text { Multiple neighbors: } \\
\text { Replacement: } \\
\text { Caliper: }\end{array}$ & $\begin{array}{c}\text { yes } \\
\text { with } \\
c=0.001\end{array}$ & $\begin{array}{c}\text { yes } \\
\text { with } \\
c=0.002\end{array}$ & $\begin{array}{c}\text { yes } \\
\text { with } \\
--\end{array}$ & $\begin{array}{c}\text { no } \\
\text { with } \\
c=0.001\end{array}$ & $\begin{array}{c}\text { no } \\
\text { with } \\
c=0.002\end{array}$ & $\begin{array}{c}\text { no } \\
\text { with } \\
--\end{array}$ \\
\hline \multirow{6}{*}{$\begin{array}{c}\text { Treatment (1) } \\
\text { vs. } \\
\text { no treatment (0) }\end{array}$} & ATT & 1.7499 & 2.6029 & 2.6771 & 2.0326 & 2.9091 & 2.7003 \\
\hline & t-statistic & 1.83 & 2.88 & 2.99 & 1.95 & 2.89 & 2.44 \\
\hline & Treated on support & 336 & 451 & 605 & 336 & 451 & 605 \\
\hline & Untreated on support & 788 & 788 & 788 & 788 & 788 & 788 \\
\hline & Average difference in propensity score & 0.0004 & 0.0007 & 0.0016 & 0.0004 & 0.0007 & 0.0016 \\
\hline & & $(0.0003)$ & $(0.0005)$ & $(0.0021)$ & $(0.0003)$ & $(0.0005)$ & $(0.0021)$ \\
\hline \multirow{6}{*}{$\begin{array}{c}\text { Pre-treatment (1) } \\
\text { Vs. } \\
\text { treatment }(0)\end{array}$} & ATT & -4.3187 & -3.3580 & -3.5383 & -4.4330 & -4.0428 & -3.6823 \\
\hline & t-statistic & -3.04 & -2.72 & -3.22 & -3.08 & -3.03 & -2.81 \\
\hline & Pre-treated on support & 144 & 188 & 236 & 144 & 188 & 236 \\
\hline & Treated on support & 543 & 543 & 543 & 543 & 543 & 543 \\
\hline & Average difference in propensity score & 0.0004 & 0.0006 & 0.0021 & 0.0004 & 0.0006 & 0.0021 \\
\hline & & $(0.0003)$ & $(0.0005)$ & $(0.0052)$ & $(0.0003)$ & $(0.0005)$ & $(0.0052)$ \\
\hline \multirow{6}{*}{$\begin{array}{l}\text { Pre-treatment (1) } \\
\text { vs. } \\
\text { no treatment }(0)\end{array}$} & ATT & -1.6306 & 0.0049 & -1.0540 & -2.0814 & 0.0070 & -0.6630 \\
\hline & t-statistic & -0.81 & 0.00 & -0.68 & -1.03 & 0.00 & -0.38 \\
\hline & Pre-treated on support & 87 & 120 & 211 & 87 & 120 & 211 \\
\hline & Untreated on support & 604 & 604 & 604 & 604 & 604 & 604 \\
\hline & Average difference in propensity score & 0.0003 & 0.0007 & 0.0043 & 0.0003 & 0.0007 & 0.0043 \\
\hline & & $(0.0003)$ & $(0.0006)$ & $(0.0075)$ & $(0.0003)$ & $(0.0006)$ & $(0.0075)$ \\
\hline
\end{tabular}

Notes: Propensity matching estimation; outcome variable is school readiness score; explanatory variables as in model (4) in Tables 4, 5, and 6; standard errors in parentheses; ATT = average treatment effect of the treated. 


\subsection{Does the investment pay off?}

Several studies have shown that early investments can pay off in later life. At this point, we cannot quantify any potential long-run effects of $\mathrm{JU}$ attendance or provide a cost-benefit analysis. However, doing some back-of-the-envelope calculations, we can get first and admittedly tentative evidence on the relative cost effectiveness of the program.

The JU course fee for preschool children is $€ 5$, with public transportation being included in the fee. The JU management board has calculated average net costs of about $€ 100$ per child and course. This covers the instructor's salary, course materials and fixed costs (including rental for the building, utilities, staff, etc.). There are no additional costs because the kindergarten teacher's salary is paid anyway (the courses take place during regular kindergarten time). However, there are costs for public transportation for the kindergarten teacher of about $€ 20$ - which amount to $€ 1.4$ per child. Hence, the total cost per child is approximately $€ 106$. Next, look at the returns to JU. Consider, for example, model (4) in Table 4 in which school readiness increases by $2.18 \%$. Compared to the age effect, this is worth 4.4 months. But how to compensate non-participants? Extend kindergarten duration or offer alternative educational activities? Both come at a cost. For instance, the Federal Statistical Office (2012) reports total costs for publicly funded day care of about $€ 6,100$ per child per year. With on average 220 kindergarten days per year a day in kindergarten costs about $€ 28$ per child. This compares to $€ 106$ for a JU class. Our calculations are certainly not meant to serve as a full cost-benefit analysis but they can be instructive to further think about the institutional structure of early education. Children will be better prepared for school if they get additional (and exciting) extracurricular educational input. In addition, compared to investments in other intervention or early childhood programs (Duncan/Magnuson 2013, Almond/Currie 2011), the investment of $€ 106$ per child and course at Junior University is small. 
The federal program 'House of little scientists' follows the same idea as JU. Comparing those programs, the centralized JU-approach and the decentralized approach of the 'House of little scientists', could yield valuable insights. While the public funds can be tentatively estimated to be about $€ 35$ per child ${ }^{15}$, the total costs (public plus private costs) and the returns are unknown. However, without knowing the returns and the costs of the program a cost-benefit analysis is not possible, but given the large scale of the program certainly desirable. Our approach has shown how to evaluate preschool programs in Germany, using administrative data from the mandatory school entry examination to estimate the returns.

\section{Conclusion and Discussion}

Many studies analyze the impact of early childhood education on educational attainment, earnings and the probability of employment but only few studies focus on voluntary extracurricular activities and their impact on educational success. In this paper, we contribute to this topic by analyzing the effect of a unique educational project in Germany on school readiness of children. The Junior University (JU) is a private educational institution intended to supplement kindergarten and school. Besides private enrollment, kindergartens are encouraged to enroll entire preschool classes (last year before school entry) at JU, where children participate in mainly hands-on experimental science courses. Using within kindergarten variation in enrollment, we analyze the effect of participation on the school readiness of preschoolers.

\footnotetext{
${ }^{15}$ In October 2015, 4,400 Kindergartens in Germany were accredited. With about 60 children reached per year and kindergarten this amounts to 264,000 children (estimation is based on figures provided by the Wonderlabz Network for a densely populated region in North Rhine-Westphalia http://wonderlabz.org/netzwerk/). Excluding preschool teacher salaries, accreditation fees and training costs the public expenses of the program amount to $€ 35$ per child (cf. Section 1).
} 
Our main findings suggest that attending classes at JU significantly increases the abilities of preschool children by approximately $2.18 \%$ - which corresponds to three additional tasks completed in the school entry examination. To validate our results, we compare the treatment group to a pre-treatment group of children. The pre-treatment group received the treatment after their school readiness has been assessed. As a final refinement of our estimation strategy, we apply a matching approach. The estimated JU effect passes all validity and robustness checks.

What explains the positive JU effect? The JU courses are unconventional hands-on experimental courses - taught by experts and not by the kindergarten teachers. They show experiments that children are typically not exposed to at kindergarten or at home, e. g. building volcanoes of sand and blasting them with peas. The event character may increase attention and foster active participation which transforms into an increase in ability. In addition, it is possible that the positive $\mathrm{JU}$ effect is further enforced by kindergarten teachers and parents. By talking about the courses, possibly repeating the experiments and discussing what has been learned, a short course can become a long lasting experience. This also raises the question on the optimal intensity, the quality of the courses and duration of the program. But clearly, the exact channel through which the program works, its intensity and whether the effect is in fact long lasting is an open issue and beyond the scope of the present paper. However - and this is in line with the literature on investment in early childhood education the children in our data are young and accumulation of skills and knowledge is known to be higher in early life (e.g. Shonkoff/Philipps 2000, Cunha et al. 2006). That's why doing just a little bit more significantly improves school readiness. 


\section{Acknowledgments}

We thank the health office of the city of Wuppertal for making SEnMed data available and the statistics office for regional data and support. This research was partly funded by the Mercator Foundation, Essen, whose support is gratefully acknowledged. 


\section{References}

Almond, D.; Currie, J. (2011): Human Capital Development before Age Five. In: Card D.; Ashenfelter, O. (eds.): Handbook of Labor Economis, Vol. 4, Part B, 1315-1486.

Barnett, W. S. (1995): Long-Term Effects of Early Childhood Programs on Cognitive and School Outcomes. In: The Future of Children, 5(3), 25-50.

Belfield, C. R.; Nores, M.; Barnett, S.; Schweinhart, L. (2006): The High/Scope Perry Preschool Program. In: Journal of Human Resources, 60(1), 162-190.

Blau, D.; Currie, J. (2006) Preschool, Day Care, and After-School Care: Who's Minding the Kids? In: Hanushek, E. A.; Welch, F. (eds.): Handbook of the Economics of Education, Vol. II, Amsterdam: Elsevier, 1163-1278.

Burger, K. (2010): How does early childhood care and education affect cognitive development? An international review of the effects of early interventions for children from different social backgrounds. In: Early Childhood Research Quarterly, 25(2), 140-165.

Cunha, F.; Heckman, J. J.; Lochner L. J.; Masterov, D. V. (2006): Interpreting the Evidence on Life Cycle Skill Formation. In: Hanushek, E. A.; Welch, F. (eds.): Handbook of the Economics of Education, Vol. I, Amsterdam: Elsevier, 697-812.

Currie, J. (2001): Early Childhood Education Programs. In: Journal of Economic Perspectives, 15(2), 213-238.

Deming, D. (2009): Early Childhood Intervention and Life-Cycle Skill Development: Evidence from Head Start. In: American Economic Journal: Applied Economics, 1(3), 111-134.

Donner, A.; Klar, N. (2000): Design and Analysis of Cluster Randomization Trials in Health Research. London: Arnold. 
Duncan, G.; Magnusson, K. (2013): Investing in Preschool Programs. In: Journal of Economic Perspectives, 27(2), 109-132.

Eccles, J. S.; Barber, B. L.; Stone, M.; Hunt, J. (2003): Extracurricular Activities and Adolescent Development. In: Journal of Social Issues, 59(4), 865-889.

Federal Statistical Office (2012): Educational financial report 2012. Wiesbaden: Federal Statistical Office. [Statistisches Bundesamt (2012): Bildungsfinanzbericht 2012. Wiesbaden: Statistisches Bundesamt.]

Felfe, C.; Lechner, M.; Steinmayr, A. (2011): Sports and Child Development. IZA Discussion Paper 6105.

Heckman, J. J.; Moon, S. H.; Pinto, R.; Savelyev, P. A.; Yavitz, A. (2010): The Rate of Return to the HighScope Perry Preschool Program. In: Journal of Public Economics, 94(1-2), 114-128.

Heckman, J. J.; Raut, L. K. (2013): Intergenerational Long Term Effects of Preschool Structural Estimates from a Discrete Dynamic Programming Model. NBER Working Paper 19077.

Hille, A.; Schupp, J. (2015): How learning a musical instrument affects the development of skills. In: Economics of Education Review, 44, 56-82.

Lechner, M.; Downward, P. (2013): Heterogeneous Sports Participation and Labour Market Outcomes in England. CESifo Working Paper 4434.

Lipscomb, S. (2007): Secondary school extracurricular involvement and academic achievement: a fixed effects approach. In: Economics of Education Review, 26(4), 463-472. 
Lochner, L. (2011): Nonproduction Benefits of Education - Crime, Health, and Good Citizenship. In: Hanushek, E. A.; Machin, S.; Woessmann, L. (eds.): Handbook of the Economics of Education, Amsterdam: Elsevier, Vol. IV, 183-282.

Pfeifer, C.; Cornelißen, T. (2010): The impact of participation in sports on educational attainment. New evidence from Germany. In: Economics of Education Review, 29(1), 94-103.

Riedel, A.; Schneider, K.; Schuchart, C.; Weishaupt, H. (2010): School Choice in German Primary Schools: How binding are school districts? In: Journal of Educational Research Online, 2(1), 94-120.

Ruhm, C.; Waldfogel, J. (2012): Long-term effects of early childhood care and education. In: Nordic Economic Policy Review, 3(1), 23-51.

Schettler, H. (2010): Playing Catch-Up in German Early Science Education with ScienceLab. In: Innovations: technology, governance, globalization, 5(2), 87-101.

Schneider, K.; Schuchart, C.; Weishaupt, H.; Riedel, A. (2012): The effect of free primary school choice on ethnic groups - Evidence from a policy reform. In: European Journal of Political Economy, 28(4), 430-444.

Shonkoff, J. P.; Philipps, D. A. (2000): From Neurons to Neighbourhoods - The Science of Early Childhood Development. Washington D.C.: National Academy Press.

Stevenson, B. (2010). Beyond the Classroom: Using Title IX to Measure the Return to High School Sports. In: Review of Economics and Statistics, 92(2), 284-301. 